\title{
Accumulation of Antibiotic Resistance Genes in Pakchoi (Brassica Chinensis L.) Grown in Chicken Manure-fertilized Soil Amended With Fresh and Aged Biochars
}

\author{
Zhiming Shi \\ Shanxi University \\ Peng Zhang \\ Shanxi University \\ Yan Liu \\ Shanxi University \\ Yonghua Zhao \\ Chang'an University \\ Congying Wang ( $\nabla$ wangcongying@sxu.edu.cn ) \\ Shanxi University
}

\section{Research Article}

Keywords: fresh biochar, aged biochar, antibiotic resistance gene, pakchoi, pot experiment, rhizosphere

Posted Date: January 3rd, 2022

DOl: https://doi.org/10.21203/rs.3.rs-929900/v1

License: (c) (1) This work is licensed under a Creative Commons Attribution 4.0 International License.

Read Full License

Version of Record: A version of this preprint was published at Environmental Science and Pollution Research on February 1st, 2022. See the published version at https://doi.org/10.1007/s11356-022-189415 . 


\section{Abstract}

Biochar has been used to alleviate the contamination of antibiotic resistance genes (ARGs) in soil and to inhibit ARGs transfer from soil to plants. However, the effect of aged biochar on ARGs abundance in soil and ARGs enrichment in plants are scarcely investigated. In this study, a pot experiment was conducted to compare the effects of fresh and aged biochars on the accumulation of five typical ARGs including tet $\mathrm{X}$, tet $\mathrm{W}$, sul2, ermB and int/ in a chicken manure-fertilized soil and in pakchoi (Brassica chinensis L.). Results showed that both biochars significantly decreased the abundance of tetW, sul2, and ermB and increased the abundance of tetX and int/1 in soil. However, the accumulation of all tested ARGs in pakchoi were significantly decreased by both biochars. At the lower addition rate (1\%), the fresh biochar was superior to the aged biochar in decreasing the accumulation of some genes (tet $\mathrm{W}$, tetX, and su/2) in pakchoi, whereas an opposite tendency was observed for other genes (ermB and int $/$ ). As the addition rate increased to $2 \%$, the difference between the two biochars diminished and a similar capacity of decreasing ARGs transfer was observed. The reduction in ARGs accumulation in pakchoi was highly related to the type of ARGs, the biochar addition level and the aging of biochar. Our results provide insights into the naturally aged biochar on the fate of ARGs in a soil-plant system.

\section{Introduction}

In recent decades, antibiotics have been extensively applied in the treatment of infectious diseases of humans and animals and as feed additives in the livestock and poultry industry. These antibiotics are poorly absorbed and metabolized by animals and hence are excreted into environment (Yılmaz and Özcengiz, 2017; Xie et al., 2018). The abuse of antibiotics induces the production of antibiotic resistance genes (ARGs), which can be spread among bacteria via horizontal gene transfers. Animal manures are often a reservoir of bacteria carrying ARGs and mobile genetic elements (MGEs) (Davies and Davies, 2010; Tello et al., 2012). When animal manures are applied to farmlands as organic fertilizer to promote crop growth, ARGs could pose a potential long-term threat to the farmland ecosystem (Schmitt et al., 2006). For example, ARGs have been detected in various harvested parts of vegetables grown on manure-amended soils, including roots and leaves. The abundance and diversity of ARGs in organically produced lettuce were found to be greater than those in conventionally produced lettuce due to the higher application rates of animal manures in the former (Marti et al., 2013; Wang et al., 2015; Zhu et al., 2017). These studies indicate that ARGs can migrate from soil to plants and may enter the human body through food chains via the consumption of edible parts of contaminated crops and vegetables.

Biochar application has been widely used as a soil amendment to increase soil fertility and agricultural yields (Uchimiya et al., 2010; Wang et al., 2013; Lian and Xing, 2017). Due to its strong adsorptive capacity, biochar has recently been applied to decrease the abundance of antibiotics and ARGs in soil, as well as their transfer from soil to plants (Cui et al., 2016; Duan et al., 2017; Lu et al., 2017). In these studies, biochar is found to decrease the concentration of antibiotics directly by adsorption and indirectly by increased microbial/enzymatic degradation, which in turn alleviates the selective stress of antibiotics and reduces the abundance of ARGs. The application of biochar may also suppress the spreading and 
accumulation of ARGs by maintaining or even increasing a high microbial diversity in soil (Chen et al., 2018). In the case of heavy metal contaminated soil, where heavy metals pose a selective pressure on ARGs, biochar application often leads to a decreased abundance of ARGs by reducing the bioavailability and mobility of heavy metals (Park et al., 2011; Lu et al., 2017).

Biochar generally undergoes continuous modifications due to abiotic and biotic oxidation, solubilization, and interactions with microbes and minerals in soil, termed as "aging" (Zimmerman, 2010; Kumari et al., 2014; Wang et al., 2020). The aging processes change the physical and chemical properties of biochar, such as decrease in the specific surface area and increase in the proportion of oxygen-containing functional groups (e.g., carboxyl and hydroxyl groups) on the C matrix (Gul et al., 2015; Zhao et al., 2015; Huff and Lee, 2016). The surface charge on biochar may also vary after aging (Cheng et al., 2008). These changes in biochar characteristics can alter the adsorption ability of biochar for soil contaminants (Uchimiya et al., 2012; Yakout, 2015), including ARGs (Lian et al., 2020), which may further influence the transfer of ARGs in the biochar-amended soil-plant system. As the natural aging in soil is a very slow process, artificially aged biochars have been fabricated by chemical and physical oxidation methods to study the effects of aging on the immobilization of heavy metals and organic contaminants by biochars (Wang et al., 2020). However, the impacts of aged biochar on the transfer of ARGs from soil to plant tissues are yet to be clarified.

In this study, the effects of fresh and aged biochars on the selected ARGs (tetX, tetW, su/2, ermB, and int/1) in a soil-plant system were compared in a pot experiment grown with pakchoi (Brassica chinensis L.). tet $\mathrm{X}$ and tet $\mathrm{W}$ are two of tetracycline resistance genes, sul 2 is one of sulfonamide resistance genes, ermB is one of macrolide resistance gene. These typical genes are highly related to the above mentioned antibiotics and were usually determined by previous studies (Duan et al., 2017; Cui et al., 2018). int/1 (class 1 integronase gene) is a mobile genetic element which is capable of integrating gene cassettes into a variable region, giving the bacteria the ability to become resistant to a range of antibiotics (Partridge et al., 2009). Therefore, it was a molecular marker of antibiotic resistance (Amos et al., 2015). Aged biochar was prepared via a chemical oxidation and artificial weathering method. A chicken manure-fertilized soil, amended with chicken manure each year and continued for more than 10 years, was collected for the experiment.

\section{Materials And Methods}

\subsection{Soil sample and biochar preparation}

The soil sample was collected from 0-20 cm of an agricultural field in Lvliang, Shanxi Province, China, which has been amended with chicken manure each year for more than 10 years. Soil was manually homogenized, air-dried, and ground to pass through a 2-mm sieve after removing gravels and visible roots. The soil consists of $57.9 \%$ sand, $41.5 \%$ silt, and $0.5 \%$ clay. It contains $2.74 \%$ of organic matter and $0.31 \%$ of total nitrogen. Its other properties are listed as follows: $\mathrm{pH} 7.17$, cation exchange capacity (CEC) $27.07 \mathrm{cmol} \mathrm{kg}^{-1}$, total $\mathrm{Cu} 45.08 \mathrm{mg} \mathrm{kg}^{-1}, \mathrm{~Pb} 23.46 \mathrm{mg} \mathrm{kg}^{-1}$, and Cd $0.81 \mathrm{mg} \mathrm{kg}^{-1}$. Seeds of Shanghai 
pakchoi (Brassica chinensis L.), a representative of commonly consumed vegetables in China (Wan et al., 2014), were purchased from the Taiyuan Modern Agricultural Research Center.

The feedstock for biochar production was cornstover, which is one of the most abundant agricultural residues in Shanxi Province (Yang et al., 2020). The feedstock was subjected to pyrolysis at a temperature of $550^{\circ} \mathrm{C}$ in a muffle furnace under anoxic conditions, following the protocol proposed by Wang et al. (2013). The obtained fresh biochar (BC) was gently ground and sieved through a $2 \mathrm{~mm}$ sieve for the aging experiment. The aged biochar was prepared according to the chemical oxidation and artificial weathering method (Naisse et al., 2015; Huff and Lee, 2016). The chemical oxidation was set to stimulate the biotic or abiotic oxidization of biochar occurred in soil, while the artificial weathering was set to stimulate the physical fragmentation and breakdown caused by climate effect (Naisse et al., 2015; Wang et al., 2020). Biochar was first reacted with a $30 \%$ hydrogen peroxide $\left(\mathrm{H}_{2} \mathrm{O}_{2}\right)$ solution with a solid to solution ratio of $1: 2$ at $25 \pm 2{ }^{\circ} \mathrm{C}$ for $3 \mathrm{~h}$ under continuous stirring. The mixture was filtered and the residues retained on the filter were carefully rinsed with distilled water to remove any residual $\mathrm{H}_{2} \mathrm{O}_{2}$, and dried overnight at $105^{\circ} \mathrm{C}$ in an oven. Thereafter, the artificial weathering process consisted of repeated drying-wetting and freezing-thawing cycles. Briefly, the chemically-oxidized biochar was saturated with water and then dried overnight at $60^{\circ} \mathrm{C}$ in an oven. Then, the biochar sample was again saturated with water and frozen at $-20^{\circ} \mathrm{C}$ for one day, and then thawed at room temperature for 5 hours. Both the drying-wetting and freeze-thaw cycles were repeated three times to obtain the aged biochar (OBC).

The specific surface area and average pore size of the biochars were measured by an ASAP 2020 surface area analyzer (Micromeritics Instrument Co. Ltd., City, USA). The elemental composition of biochars was determined using an element analyzer (Flash EA1112, Thermo Finnigan, USA) and surface functional groups were analyzed using Fourier-transform infrared spectroscopy (FT-IR, Tensor 27, Bruker, Germany) using $\mathrm{KBr}$ pellets. The resolution was set to $4 \mathrm{~cm}^{-1}$ and the operating range was $400 \mathrm{~cm}^{-1}$ to $4000 \mathrm{~cm}^{-1}$. The IR spectra of different samples were normalized using the Max-Min normalization method with the OPUS software (v.7.2; Bruker, Billerica, USA). XPS spectra (survey scan, C1s and 01s) were acquired using PHI X-tool XPS instrument (Physical Electronics Inc., Chanhassen, USA). XPS data were analyzed using Thermo Scientific TM Avantage software. Charging effect was corrected using the adventitious carbon energy reference method $(284.6 \mathrm{eV})$. C1s and $01 \mathrm{~s}$ spectra were deconvoluted using a GaussianLorentzian method after baseline correction.

\subsection{Pot experiment}

The pot experiment was set up using plastic pots $(22 \mathrm{~cm}$ diameter $\times 19 \mathrm{~cm}$ height), each containing 2.0 $\mathrm{kg}$ of dry soil. The soil was mixed with biochars at the rate of $1.0 \%$ and $2.0 \%$ on a dry weight basis and equilibrated in dark for one week. A control treatment without any biochar amendment (defined as CK) was also included. Three replicates for each treatment were set. The seeds of pakchoi (Brassica chinensis L.) were germinated in petri dishes (Khan et al., 2015). Six germinated seeds were transplanted to each pot and 2 plants was left after thinning. Soil water content was maintained to $60 \%$ of water 
holding capacity by adding distilled water on the soil surface every two days. All pots were placed in a greenhouse with natural light intensity and humidity at $22 \pm 6{ }^{\circ} \mathrm{C}$ during the entire cultivation period.

Following a 75-day cultivation, plants (including root and leaves) were harvested and the soil was separated into rhizosphere and non-rhizosphere soil (i.e. bulk soil) according to the method described by Mestre et al. (2011). The harvested plants were carefully washed with distilled water to remove adhering soil and dried using sterilized filter paper before packing. All soil and plant samples were stored at $-80{ }^{\circ} \mathrm{C}$ for subsequent analysis.

\subsection{DNA extraction and ARGs quantification}

Prior to the DAN extraction, plant samples were processed so that the endophytes could be identified, including surface sterilization with $\mathrm{H}_{2} \mathrm{O}_{2}$, ethanol, $\mathrm{NaOCl}$ and $\mathrm{H}_{2} \mathrm{O}$ following the procedure described by Gottel et al. (2011). Then plant samples were cut it into pieces with sterilized scissors, and then ground in liquid nitrogen to a powder (Cui et al., 2018). Total genomic DNA was extracted from soil and plant samples of $0.5 \mathrm{~g}$ using the E. Z. N. A. ${ }^{\text {TM }}$ Mag-Bind Soil DNA Kit (Omega Bio-tek, USA), following the manufacturer's instructions. The plant samples were ground in liquid nitrogen before extraction. The genomic DNA extracted was stored at $-20^{\circ} \mathrm{C}$ prior to amplification using polymerase chain reaction (PCR).

Two tetracycline resistance genes (tet $\mathrm{X}$, tet $\mathrm{W})$, sulfonamide resistance gene (su/2), macrolide resistance gene (ermB), class 1 integrase gene (int//), and 16S rRNA gene were analyzed by quantitative PCR (qPCR) using a SYBR Green approach on a TIB-8600 Real-time PCR System (TIB, Putai Bioscience, China). The ARGs primers and $16 \mathrm{~S}$ rRNA used in the qPCR are listed in Table 1. A volume of $20 \mu \mathrm{L}$ reaction mixture contained $10 \mu \mathrm{L}$ of $2 \times$ SybrGreen qPCR premixture (KAPA), $0.4 \mu \mathrm{L}$ of forward/reverse primers $(10 \mu \mathrm{M}), 1$ $\mu \mathrm{L}$ of template DNA, and $8.2 \mu \mathrm{L}$ of $\mathrm{ddH}_{2} \mathrm{O}$. Each qPCR run was conducted at $95^{\circ} \mathrm{C}$ for $5 \mathrm{~min}$ for initial denaturation, followed by 40 cycles of denaturation at $95^{\circ} \mathrm{C}$ for $15 \mathrm{~s}$, annealing at $60{ }^{\circ} \mathrm{C}$ for $30 \mathrm{~s}$, and extension at $60^{\circ} \mathrm{C}$ for $30 \mathrm{~s}$. Each reaction was run in triplicate, and negative control was also run, following the experimental samples, to ensure that no contamination of amplicons occurred. Reactions with poor melting curves or amplification efficiencies beyond $90-110 \%$ were discarded. Retained reactions had both a threshold cycle $<31$ and three positive replicates. The relative copy numbers of target genes were determined using Eq. 1 (Song et al., 2020).

$\mathrm{CN}_{\mathrm{R}}=10^{\left(31-\mathrm{C}_{\mathrm{T}}\right) /(10 / 3)}$

Where $\mathrm{C}_{\mathrm{T}}$ refers to threshold cycle and $\mathrm{CN}_{\mathrm{R}}$ represents the relative copy numbers of target genes (ARG copy number/16S rRNA gene copy number). The absolute abundance of ARGs was calculated using Eq. 2.

$\mathrm{CN}_{\mathrm{A}}=\mathrm{CN}_{\mathrm{R}} \times \mathrm{CN}_{16 \mathrm{~S}}$

Where $\mathrm{CN}_{\mathrm{A}}$ and $\mathrm{CN}_{16 \mathrm{~S}}$ refers to the absolute abundance of ARGs and 16S rRNA genes, respectively. 
The absolute abundance of 16S rRNA gene was quantified separately using standard curves with an $A B I$ 7500 system. A standard control containing plasmids with cloned and sequenced 16S rRNA gene fragment was used to generate an eight-point calibration curve from 10 -fold dilutions for calculation. All qPCRs were performed in technical triplicates with template-free negative controls.

\subsection{Statistical analysis}

Statistical analysis was conducted using SPSS 19.0 Software (SPSS Inc., Chicago, IL, USA). One-way ANOVA was conducted to evaluate the significance of the differences between means at $P<0.05$. Multifactor variance analysis was used to evaluate the effect of biochar type, biochar addition rate $(0 \%, 1 \%$, and $2 \%$ ), and planting (rhizosphere/non-rhizosphere soil) and their interactions on ARGs abundances in soil. SigmaPlot (Version 12.0) was used for plotting the graphs.

\section{Results And Discussion}

\subsection{Biochar characterization}

Selected physical and chemical properties of fresh biochar $(B C)$ and aged biochars $(\mathrm{OBC})$ are presented in Table 2. $\mathrm{pH}$ value decreased from 9.37 for $\mathrm{BC}$ to 8.18 for $\mathrm{OBC}$. The $\mathrm{CEC}$ value increased from 12.20 $\mathrm{cmol} \mathrm{kg}^{-1}$ for $\mathrm{BC}$ to $27.12 \mathrm{cmol} \mathrm{kg}^{-1}$ for OBC. CEC can be serve a way to measure biochar oxidation, with greater sensitivity than the $\mathrm{O} / \mathrm{C}$ ratio (Hale et al., 2011). The increased CEC indicated the surface oxidation of OBC. The Brunauer-Emmett-Teller (BET) surface area decreased by $60.1 \%$ from BC (104.21 $\left.\mathrm{m}^{2} \mathrm{~g}^{-1}\right)$ to OBC $\left(41.56 \mathrm{~m}^{2} \mathrm{~g}^{-1}\right)$, indicating that aging decreased the specific surface area of biochar. This is consistent with Ghaffar et al. (2015) that the specific surface area of biochar reduced by $26-66 \%$ after aging by an oxidation treatment. The possible reasons include collapse of inner pores and the formation of oxygen-containing functional groups at pore entrances (Chang et al., 2018).

Aging also modified the elemental composition of biochars; the contents of $\mathrm{C}$ and $\mathrm{H}$ decreased while the $\mathrm{N}$ and $\mathrm{O}$ contents increased after aging (Table 2). As a result, the $\mathrm{O} / \mathrm{C}$ ratio increased from 0.11 in $\mathrm{BC}$ to 0.15 in $\mathrm{OBC}$, indicating that oxygen-containing functional groups have been introduced by aging (Uchimiya et al., 2011; Huff and Lee, 2016). As the $(0+N) / C$ ratio is an indicator of polarity (Chen et al., 2005), its increase suggested that $O B C$ had a greater polarity than $B C$.

The FTIR spectra of the $\mathrm{BC}$ and $\mathrm{OBC}$ were similar, suggesting they shared similar types of functional groups (Fig. 1a). For a close inspection of the intensity changes of functional groups after aging, we calculated the difference spectrum by subtracting the normalized spectrum of $\mathrm{OBC}$ from that of the BC (Fig. 1b). Three distinct IR transmittance peaks appeared in the difference spectrum at ca. $1400 \mathrm{~cm}^{-1}$, $1575 \mathrm{~cm}^{-1}$ and $1700 \mathrm{~cm}^{-1}$. Peaks at ca. $1400 \mathrm{~cm}^{-1}$ and $1575 \mathrm{~cm}^{-1}$ corresponded to the asymmetric and symmetric modes of COO- functional group, respectively. The peak at $1700 \mathrm{~cm}^{-1}$ was assigned to the stretching mode of $\mathrm{C}=\mathrm{O}$ (Ameur et al., 2018; Ren et al., 2018). These results indicated that O-containing functional groups were enriched after aging, which is in agreement with the observed increased in $\mathrm{O} / \mathrm{C}$ 
ratio of the aged biochar $(\mathrm{OBC})$. This statement is further supported by the results of XPS analysis. The XPS analysis showed that the $\mathrm{OBC}$ had higher $\mathrm{O}$ content than its fresh counterpart of BC (Fig. 2), in particular the proportion of $\mathrm{O}$ associated with $\mathrm{C}=\mathrm{O}$ in $\mathrm{OBC}$ was much higher than that in $\mathrm{BC}$ (Fig. 2). In summary, aging increased the intensities of oxygen-containing functional groups, including carboxyl and carbonyl, on the biochar's surface. Such changes may alter the interaction between biochar and ARGs.

\subsection{Effects of biochar amendments on antibiotic resistance genes (ARGs) in soil}

The relative abundances (in relative to the total 16S rRNA copy) of ARGs in chicken manure-fertilized soil as affected by fresh biochar and aged biochar amendments are shown in Fig. 3. int/ had the highest relative abundance, with a magnitude of $10^{-2}$. The relative abundances of the other ARGs ranged at $10^{-}$

${ }^{3}$ to $10^{-4}$, following a decreasing order of $s u / 2>\operatorname{ermB}>\operatorname{tet} \mathrm{X}>\operatorname{tet} \mathrm{W}$. Fig. 3 showed that biochar amendments may inhibit or promote the abundance of ARGs in the soil depending on the ARG species. Moreover, the abundance of ARGs in the rhizosphere soil was much different to that in the nonrhizosphere soil. To make a clear presentation, the ARGs abundance in the rhizosphere soil and in the non-rhizosphere soil was described separately as follows.

\subsubsection{Comparative effects of fresh biochar and aged biochar on ARGs in rhizosphere soil}

The relative abundances of tet $\mathrm{W}$, sul2, and ermB genes in the rhizosphere soil generally decreased in both $\mathrm{BC}$ and $\mathrm{OBC}$ treatments as compared to the control ( $\mathrm{CK}$, without biochar), and the decreased amount in the rhizosphere soil was $15.0-24.3 \%, 27.6-74.7 \%$, and $18.8-54.4 \%$ for tetW, sul2 and ermB, respectively $(\mathrm{P}<0.05)$ (Fig. 3a, C, d). However, the abundances of tetX and int/1 increased significantly in both biochar treatments $(P<0.05$, Fig. 3b, e). More specifically, the abundance of tetX and int/1 in the rhizosphere soils was 1.5-5.7 times and 2.3-3.5 times higher, respectively, than that of CK. int/1 is a proxy of antibiotic resistance and an indicator of mobile genetic elements (Amos et al., 2015; Duan et al., 2017). The increased abundance of int $/ 1$ indicated that both $B C$ and $O B C$ increased the risk of horizontal transfer of ARGs in soil. Moreover, the aged biochar $\mathrm{OBC}$ had a highly stronger increasing effect than that of fresh biochar BC $(P<0.05$, Fig. 3e).

On the effects of $B C$ and $O B C$ on the ARGs abundance in the rhizosphere soil, there was no significant difference between the two types of biochars in decreasing the abundances of tet $\mathrm{W}$, ermB and su/2 $(P>0.05)$; while OBC showed a significant effect than $B C$ on increasing the abundances of tetX and int/ $(P<0.05)$. These results suggested that the aging of biochar had negligible effect on the accumulations of tet $\mathrm{W}, \mathrm{erm} \underline{\mathrm{B}}$ and sul2 but increased the potentials of tetX accumulation and the horizontal transfer of ARGs in the rhizosphere soil. Given that the occurrence of ARGs in soil is regulated by microorganisms which carry these ARGs (Dantas and Sommer, 2014), the decreases of tetW, ermB and su/2 suggest the downregulated producing of these genes, while the increased accumulations of tet $\mathrm{X}$ and int/ 1 indicate the upregulated producing of tetX and int/1 as influenced by biochar addition.

\subsubsection{Comparative effects of fresh biochar and aged biochar on ARGs in the non-rhizosphere soil}


Similarly, the abundance of tetW, sul2, and ermB genes was decreased by biochar addition, with a decreasing amount of $15.8-58.5 \%$ (Fig. 3a, c, d). In contrast, the abundance of tetX and int/ increased by $6.5 \%-155.8 \%$ (Fig. 3b, e). Both biochars showed no significant difference in the abundance of tetW, sul2, and ermB ( $>>0.05)$, especially at a higher biochar application rate. However, the fresh biochar was superior to the aged biochars in increasing the abundance of tetX and int/1 in the non-rhizosphere soil $(P<0.05)$. This result suggested that the aging of biochar had an opposite effect on the accumulation of tet $\mathrm{X}$ and int $/ 1$ in the non-rhizosphere soil versus the rhizosphere soil.

Rhizosphere soil has been a focused area in research regarding transmission of ARGs (Cui et al., 2018; Song et al., 2020). In the present study, the ARGs abundance in the rhizosphere was generally lower than that in the non-rhizosphere soil, especially in CK (Fig. 3), indicating that planting could significantly decrease the ARGs abundances in the rhizosphere soil, likely owing to the root exudates such as sugars, organic acids, and amino acids, which may create a low selective pressure of the antibiotics (Doornbos et al., 2012; Jechalke et al., 2013). In addition, the rhizosphere soil always creates conditions favorable for higher functional and microbial diversity than the non-rhizosphere soil which may also contributes to the decreased ARGs abundance (Nannipieri et al., 2008; Chen et al., 2018; Compant et al., 2019; Rivas et al., 2022).

The addition of biochar decreased the abundance of some genes while increased the abundance of others, both in the rhizosphere and non-rhizosphere soils. Some previous studies have shown that the application of biochar in soil reduced the dissemination of ARGs in soil (Ye et al., 2016; Liang et al., 2017; Jiao et al., 2018). This was attributed to the high specific surface area and microporous structure of biochar which could adsorb antibiotics and heavy metals, resulting in a decrease in their bioavailability. Moreover, the surface and porous structure could promote the hydrolysis and photolysis of antibiotics, providing a niche for antibiotic degrading bacteria as well, thus resulting the lower antibiotic concentrations in soil (Ye et al., 2016; Duan et al., 2017). These together attenuate the selective pressure on ARGs. On the other hand, there are also studies showing that the addition of biochar increased the abundance of some ARGs in soil. For example, Cui et al. (2018) found that the abundance of tet (tetX, tetG-01, tetG-02 tetM-01 tetM-02), sul (su/1 and su/2), and int/1 was increased in soil after 60 days of biochar amendment. The phenomenon was attributed to the pore structure and larger specific surface area of biochar which offer a niche for antibiotic-resistant bacteria (Ye et al., 2016). Apart from this, the bacterial biofilms formed within biochar and their proximity might contribute to an increase in the abundance of ARGs due to quorum sensing (Zheng et al., 2018).

To explore the effect of biochar type (BC/OBC), biochar addition rate $(0 \%, 1 \%$, and $2 \%)$, and planting (rhizosphere/non-rhizosphere soil) and their interactions on ARGs abundances in soil, multi-factor variance analysis was used and the results are presented in Table 3. Both biochar type and biochar addition rate had a remarkable effect on the abundance some ARGs. Specifically, biochar type significantly influenced genes of tet $\mathrm{W}$, tetX, ermB and int/1 while biochar addition rate significantly affected genes of tetW, sul2 and ermB $(P<0.05)$, indicating that the change of ARGs abundance in soil as affected by biochar was highly related to the ARGs species, the biochar addition level and its aging in 
soil. Table 3 shows that all tested genes were distinctively affected by planting, suggesting the distribution of ARGs abundance in rhizosphere soil was absolutely different from that in the nonrhizosphere soil $(\mathrm{P}<0.001)$. In addition, planting improved the performance of biochar (including its types and addition level) on ARGs abundance and significant interactive effects were observed among planting, biochar type, and biochar addition rate (Table 3).

\subsection{ARGs enrichment in pakchoi}

Shown in Fig. 4 are the relative abundance of ARGs in pakchoi after cultivation for 75 days. All selected genes (tetX, tetW, sul2, ermB and int/ ) were detected in pakchoi tissues, suggesting that these genes were transferred from soil to the plant. Some root endophytes harboring ARGs might be responsible for the ARGs transfer. These endophytes inhabited in the interior of the roots via the stoma or mechanical injuries, allowing ARGs to reach the leaves (Hardoim et al., 2008; Bulgarelli et al., 2012).

The relative abundances of the abovementioned genes in pakchoi were significantly reduced by biochar addition, regardless of biochar type, with only one exception (that the fresh biochar applied at a lower rate increased the relative abundance of ermB in Fig. 4d). In comparison to CK (without biochar), the abundance of tetX, tet $\mathrm{W}$, sul2, ermB, and int/1 in $\mathrm{BC}$ treatments decreased by $73.9-86.1 \%, 74.1-91.3 \%$, 25.7-85.2\%, 76.8-87.2\%, and 58.7-93.4\%, respectively. A similar pattern was observed for OBC treatments, where the corresponding genes decreased by $50.0-64.7 \%, 64.5-88.0 \%, 18.9-93.7 \%, 55.4-89.2 \%$, and $71.7-$ $95.4 \%$, as compared with CK.

The reduction in ARGs accumulation in pakchoi could not be explained by the effects of biochar on the abundance of ARGs in either the rhizosphere or the non-rhizosphere soils. Although tetX and int/1 were less accumulated in the plant in the biochar treatments than CK, their abundances in soil was significantly increased by both fresh biochar and aged biochar additions. It suggested that the promoted abundance of ARGs in soil by biochar addition does not indicate an increasing risk of ARGs contamination in plants. The possible reason was due to that the antibiotic resistance bacteria which carry these genes could not be transferred to the other parts of the plant (Duan et al., 2017).

At $1 \%$ biochar application rate, $\mathrm{BC}$ showed significantly stronger effect than $\mathrm{OBC}(\mathrm{P}<0.05)$ on the abundance of some genes (tet $\mathrm{W}$, tet $\mathrm{X}$, and su/2), whereas an opposite trend was observed on the abundance of other genes (ermB and int/1). As biochar application rate increased to $2 \%$, the difference between $\mathrm{BC}$ and $\mathrm{OBC}$ treatments diminished gradually and no significant difference between $\mathrm{BC}$ and $\mathrm{OBC}$ on the abundance of tet $\mathrm{W}$, tet $\mathrm{X}$ and ermB ( $\mathrm{P}>0.05$; Fig.4). The difference in ARGs accumulation in plants could be partly attributed to the changes of microbial community composition both in the soil and the plant (Forsberg et al., 2014; Jia et al., 2015; Sun et al., 2018; Awasthi et al., 2021). Future work with DNA sequencing should be performed in order to link the microbial community composition to the pattern of ARGs in plants, which could help better understand the biochar's influence on ARGs transfer in the soilplant system. 
Although the process of biochar aging in the present study is somehow different to that occurs in the natural environment, changes in biochar properties tended to be similar. The surface area of biochar was reduced during the artificial aging process. In the natural environment, biochar undergoes slow aging process which also results in the decrease in its specific surface area. In addition, both aging processes caused the loss of liable organic fractions (e.g. extractable organic matter) and the formation of oxygencontaining functional groups. Therefore, our results obtained using an artificially aged biochar could provide insights into the effects of naturally aging on the biochar-mediated accumulation of ARGs in soils and plants.

\section{Conclusions}

The present study compared the effects of fresh biochar and artificially aged biochar on the accumulation of selected ARGs in pakchoi using a pot experiment. The accumulation of ARGs in pakchoi was significantly reduced by biochar additions. The extent of reduction was depended on the type of ARGs, the application rate of biochar as well as the aging of biochar. In general, the abundance of ARGs in pakchoi decreased to a larger extent at a higher biochar application rate. The fresh biochar performed better than the aged biochar in reducing the accumulation of most of tested ARGs in pakchoi. However, for the macrolide resistance gene ermB and the mobile genetic element int $/$, the aging of biochar enhanced the reducing effect of biochar on their accumulation in pakchoi. The reduction in ARGs accumulation in pakchoi could not be explained by the effects of biochar on the abundance of ARGs in either the rhizosphere or the non-rhizosphere soils. Biochar additions decreased the abundance of some genes while increased the abundance of others in soil. Future research should be dedicated to the investigation of microbial community composition in the biochar-soil-plant system in order to mechanistically understand the effects of biochar and its aging process on the accumulation of ARGs in the soil and on the transfer of ARGs from the soil to the plant.

\section{Declarations}

\section{Acknowledgments}

This work was financed by the Fund Project of Shaanxi Key Laboratory of Land Consolidation (2019ZD03), the Natural Science Foundation of China (No. 4217070771) and a grant from Shanxi Laboratory for Yellow River. The authors gratefully acknowledge the anonymous reviewers and Dr. Tao Wang (from Institute of Mountain Hazards and Environment, Chinese Academy of Sciences, China) for their valuable comments and constructive suggestions.

Ethics approval and consent to participate Not applicable.

Consent for publication Not applicable.

Availability of data and materials All data generated or analyzed during this study are included in this manuscript. 
Competing interests The authors declare that they have no competing interests.

Funding This work was financed by the Fund Project of Shaanxi Key Laboratory of Land Consolidation (2019-ZD03), the Natural Science Foundation of China (No. 42177258) and a grant from Shanxi Laboratory for Yellow River.

Authors' contributions Zhiming Shi designed the experiment and wrote the original paper, Yan Liu carried out the experiment and collected the data, Peng Zhang analyzed and interpreted the data. Congying Wang and Yonghua Zhao finished the final revising and editing of the manuscript. All authors read and approved the final manuscript.

\section{References}

1. Ameur D, Zehetner F, Johnen S, Jöchlinger L, Pardeller G, Wimmer B, Rosner F, Faber F, Dersch G, Zechmeister-Boltenstern S, Mentler A, Soja G, Keiblinger KM (2018) Activated biochar alters activities of carbon and nitrogen acquiring soil enzymes. Pedobiologia 69:1-10

2. Amos GCA, Gozzard E, Carter CE, Mead A, Bowes MJ, Hawkey PM, Zhang L, Singer AC, Gaze WH, Wellington EMH (2015) Validated predictive modelling of the environmental resistome. The International Society for Microbial Ecology Journal 9:1467-1476

3. Awasthi SK, Duan Y, Liu T, Zhang Z, Pandey A, Varjani S, Awasthi MK, Taherzadeh MJ (2021) Can biochar regulate the fate of heavy metals $(\mathrm{Cu}$ and $\mathrm{Zn}$ ) resistant bacteria community during the poultry manure composting? J Hazard Mater 406:124593

4. Bulgarelli D, Rott M, Schlaeppi K, Loren V, van Themaat E, Ahmadinejad N, Assenza F, Rauf P, Huettel B, Reinhardt R, Schmelzer E, Peplies J, Gloeckner FO, Amann R, Eickhorst T, Schulze-Lefert P (2012) Revealing structure and assembly cues for Arabidopsis root-inhabiting bacterial microbiota. Nature 488:91-95

5. Chang Z, Tian L, Wu M, Dong X, Peng J, Pan B (2018) Molecular markers of benzene polycarboxylic acids in describing biochar physiochemical properties and sorption characteristics. Environ Pollut 237:541-548

6. Chen B, Johnson EJ, Chefetz B, Zhu L, Xing B (2005) Sorption of Polar and Nonpolar Aromatic Organic Contaminants by Plant Cuticular Materials. Role of Polarity and Accessibility. Environmental Science \& Technology

7. Chen Q-L, Fan X-T, Zhu D, An X-L, Su J-Q, Cui L (2018) Effect of biochar amendment on the alleviation of antibiotic resistance in soil and phyllosphere of Brassica chinensis L. Soil Biol Biochem 119:7482

8. Cheng C-H, Lehmann J, Engelhard MH (2008) Natural oxidation of black carbon in soils: Changes in molecular form and surface charge along a climosequence. Geochim Cosmochim Acta 72:15981610 
9. Compant S, Samad A, Faist H, Sessitsch A (2019) A review on the plant microbiome: Ecology, functions, and emerging trends in microbial application. J Adv Res 19:29-37

10. Cui E, Wu Y, Zuo Y, Chen H (2016) Effect of different biochars on antibiotic resistance genes and bacterial community during chicken manure composting. Bioresour Technol 203:11-17

11. Cui EP, Gao F, Liu Y, Fan X-Y, Li Z-Y, Du Z-J, Hu C, Neal AL (2018) Amendment soil with biochar to control antibiotic resistance genes under unconventional water resources irrigation: proceed with caution. Environ Pollut 240:475-484

12. Dantas G, Sommer M (2014) How to fight back against antibiotic resistance. Am Sci 102:42-51

13. Davies J, Davies D (2010) Origins and evolution of antibiotic resistance. Microbiol Mol Biol Rev 73:417-433

14. Doornbos RF, van Loon LC, Bakker PAHM (2012) Impact of root exudates and plant defense signaling on bacterial communities in the rhizosphere. A review. Agron Sustain Dev 32:227-243

15. Duan M, Li H, Gu J, Tuo X, Sun W, Qian X, Wang X (2017) Effects of biochar on reducing the abundance of oxytetracycline, antibiotic resistance genes, and human pathogenic bacteria in soil and lettuce. Environ Pollut 224:787-795

16. Forsberg KJ, Patel S, Gibson MK, Lauber CL, Knight R, Fierer N, Dantas G (2014) Bacterial phylogeny structures soil resistomes across habitats. Nature 509:612-616

17. Ghaffar A, Ghosh S, Li F, Dong X, Zhang D, Wu M, Li H, Pan B (2015) Effect of biochar aging on surface characteristics and adsorption behavior of dialkyl phthalates. Environ Pollut 206:502-509

18. Gottel NR, Castro HF, Kerley M, Yang Z, Pelletier DA, Podar M, Karpinets T, Uberbacher E, Tuskan GA, Vilgalys R, Doktycz MJ, Schadt CW (2011) Distinct microbial communities within the endosphere and rhizosphere of Populus deltoides roots across contrasting soil types. Appl Environ Microbiol 77:5934-5944

19. Gul S, Whalen JK, Thomas BW, Sachdeva V, Deng H (2015) Physico-chemical properties and microbial responses in biochar-amended soils: mechanisms and future directions. Agric Ecosyst Environ 206:46-59

20. Hale S, Hanley K, Lehmann J, Zimmerman A, Cornelissen G (2011) Effects of chemical, biological, and physical aging as well as soil addition on the sorption of pyrene to activated carbon and biochar. Environ Sci Technol 45:10445-10453

21. Hardoim PR, van Overbeek LS, Elsas JDv (2008) Properties of bacterial endophytes and their proposed role in plant growth. Trends Microbiol 16:463-471

22. Huff MD, Lee JW (2016) Biochar-surface oxygenation with hydrogen peroxide. Journal of Environmental Economics \& Management 165:17-21

23. Jechalke S, Kopmann C, Rosendahl I, Groeneweg J, Weichelt V, Krögerrecklenfort E, Brandes N, Nordwig M, Ding G-C, Siemens J, Heuer H, Smalla K (2013) Increased abundance and transferability of resistance genes after field application of manure from sulfadiazine-treated pigs. Appl Environ Microbiol 79:1704-1711 
24. Jia S, Shi P, Hu Q, Bing L, Tong Z, Zhang XX (2015) Bacterial community shift drives antibiotic resistance promotion during drinking water chlorination. Environ Sci Technol 49:12271-12279

25. Jiao W, Du R, Ye M, Sun M, Feng Y, Wan J, Zhao Y, Zhang Z, Huang D, Du D, Jiang X (2018) 'Agricultural waste to treasure' - biochar and eggshell to impede soil antibiotics/antibiotic resistant bacteria (genes) from accumulating in Solanum tuberosum L. Environ Pollut 242:2088-2095

26. Khan S, Waqas M, Ding F, Shamshad I, Arp HPH, Li G (2015) The influence of various biochars on the bioaccessibility and bioaccumulation of PAHs and potentially toxic elements to turnips (Brassica rapa L.). J Hazard Mater 300:243-253

27. Kumari KGID, Moldrup P, Paradelo M, de Jonge LW (2014) Phenanthrene sorption on biocharamended soils: application rate, aging, and physicochemical properties of soil. Water Air Soil Pollut 225:1-13

28. Lian F, Xing B (2017) Black carbon (biochar) in water/soil environments: molecular structure, sorption, stability, and potential risk. Environ Sci Technol 51:13517-13532

29. Lian F, Yu W, Zhou Q, Gu S, Wang Z, Xing B (2020) Size Matters: Nano-biochar triggers decomposition and transformation inhibition of antibiotic resistance genes in aqueous environments. Environ Sci Technol 54:8821-8829

30. Liang Y, Pei M, Wang D, Cao S, Xiao X, Sun B (2017) Improvement of soil ecosystem multifunctionality by dissipating manure-induced antibiotics and resistance genes. Environ Sci Technol 51:4988-4998

31. Lu K, Yang X, Gielen G, Bolan N, Ok YS, Niazi NK, Xu S, Yuan G, Chen X, Zhang X, Liu D, Song Z, Liu X, Wang $\mathrm{H}$ (2017) Effect of bamboo and rice straw biochars on the mobility and redistribution of heavy metals (Cd, Cu, Pb and Zn) in contaminated soil. J Environ Manage 186:285-292

32. Marti R, Scott A, Tien YC, Murray R, Sabourin L, Zhang Y, Topp E (2013) Impact of manure fertilization on the abundance of antibiotic resistant bacteria and frequency of detection of antibiotic resistance genes in soil and on vegetables at harvest. Appl Environ Microbiol 79:5701-5709

33. Mestre MC, Rosa CA, Safar SV, Libkind D, Fontenla SB (2011) Yeast communities associated with the bulk-soil, rhizosphere and ectomycorrhizosphere of a Nothofagus pumilio forest in northwestern Patagonia, Argentina. FEMS Microbiol Ecol 78:531-541

34. Naisse C, Girardin C, Lefevre R, Pozzi A, Maas R, Stark A, Rumpel C (2015) Effect of physical weathering on the carbon sequestration potential of biochars and hydrochars in soil. Global Change Biology Bioenergy 7:488-496

35. Nannipieri P, Ascher J, Ceccherini MT, Landi L, Pietramellara G, Renella G, Valori F (2008) Effects of root exudates in microbial diversity and activity in rhizosphere soils.. in: In: Nautiyal CS, Dion P (eds) Molecular Mechanisms of Plant and Microbe Coexistence. Springer Berlin Heidelberg, Berlin, Heidelberg, pp 339-365

36. Park JH, Choppala GK, Bolan NS, Chung JW, Chuasavathi T (2011) Biochar reduces the bioavailability and phytotoxicity of heavy metals. Plant Soil 348:439-451 
37. Partridge SR, Tsafnat G, Coiera E, Iredell JR (2009) Gene cassettes and cassette arrays in mobile resistance integrons. FEMS Microbiol Rev 33:757-784

38. Ren X, Yuan X, Sun H (2018) Dynamic changes in atrazine and phenanthrene sorption behaviors during the aging of biochar in soils. Environmental Science \& Pollution Research 25:81-90

39. Rivas GA, Semorile L, Delfederico L (2022) Microbial diversity of the soil, rhizosphere and wine from an emerging wine-producing region of Argentina. LWT-Food Science and Technology 153:112429

40. Schmitt H, Stoob K, Hamscher G, Smit E, Seinen W (2006) Tetracyclines and tetracycline resistance in agricultural soils: microcosm and field studies. Microb Ecol 51:267-276

41. Song M, Peng K, Jiang L, Zhang D, Luo C (2020) Alleviated antibiotic resistant genes in rhizosphere of agricultural soils with low antibiotic concentration. J Agric Food Chem 68:2457-2466

42. Sun W, Gu J, Wang X, Qian X, Tuo X (2018) Impacts of biochar on the environmental risk of antibiotic resistance genes and mobile genetic elements during anaerobic digestion of cattle farm wastewater. Bioresour Technol 256:342-349

43. Tello A, Austin B, Telfer TC (2012) Selective pressure of antibiotic pollution on bacteria of importance to public health. Environ Health Perspect 120:1100-1106

44. Uchimiya M, Bannon DI, Wartelle LH (2012) Retention of heavy metals by carboxyl functional groups of biochars in small arms range soil. J Agric Food Chem 60:1798-1809

45. Uchimiya M, Chang S, Klasson KT (2011) Screening biochars for heavy metal retention in soil: role of oxygen functional groups. J Hazard Mater 190:432-441

46. Uchimiya M, Lima IM, Klasson KT, Wartelle LH (2010) Contaminant immobilization and nutrient release by biochar soil amendment: roles of natural organic matter. Chemosphere 80:935-940

47. Wan H, Liu R, Sun H, Yu X, Liu D (2014) Caco-2 cell-based antioxidant activity of 36 vegetables commonly consumed in China. Journal of Food and Nutrition Research 2:88-95

48. Wang C, Wang T, Li W, Yan J, Li Z, Ahmad R, Herath SK, Zhu N (2013) Adsorption of deoxyribonucleic acid (DNA) by willow wood biochars produced at different pyrolysis temperatures. Biol Fertil Soils 50:87-94

49. Wang FH, Qiao M, Chen Z, Su JQ, Zhu YG (2015) Antibiotic resistance genes in manure-amended soil and vegetables at harvest. J Hazard Mater 299:215-221

50. Wang L, O'Connor D, Rinklebe J, Ok YS, Tsang DCW, Shen Z, Hou D (2020) Biochar aging: mechanisms, physicochemical changes, assessment, and Implications for field applications. Environ Sci Technol 54:14797-14814

51. Xie WY, Shen Q, Zhao FJ (2018) Antibiotics and antibiotic resistance from animal manures to soil: a review. Eur J Soil Sci 69:181-195

52. Yakout SM (2015) Monitoring the changes of chemical properties of rice straw-derived biochars modified by different oxidizing agents and their adsorptive performance for organics. Bioremediat $\mathrm{J}$ 19:171-182 
53. Yang Y, Zhou B, Lin ZHU, H (2020) The effects of nano-biochar on maize growth in northern Shaanxi Province on the Loess Plateau. Appl Ecol Environ Res 18:2863-2877

54. Ye M, Sun M, Feng Y, Wan J, Xie S, Tian D (2016) Effect of biochar amendment on the control of soil sulfonamides, antibiotic-resistant bacteria, and gene enrichment in lettuce tissues. J Hazard Mater 309:219-227

55. Yılmaz Çd, Özcengiz G (2017) Antibiotics: pharmacokinetics, toxicity, resistance and multidrug efflux pumps. Biochem Pharmacol 133:43-62

56. Zhao R, Coles N, Kong Z, Wu J (2015) Effects of aged and fresh biochars on soil acidity under different incubation conditions. Soil Tillage Res 146:133-138

57. Zheng J, Chen T, Chen H (2018) Antibiotic resistome promotion in drinking water during biological activated carbon treatment: is it influenced by quorum sensing? Sci Total Environ 612:1-8

58. Zhu B, Chen Q, Chen S, Zhu YG (2017) Does organically produced lettuce harbor higher abundance of antibiotic resistance genes than conventionally produced? Environ Int 98:152-159

59. Zimmerman AR (2010) Abiotic and microbial oxidation of laboratory-produced black carbon (biochar). Environ Sci Technol 44:1295-1301

\section{Tables}

Table 1 The information of PCR primers in this study

\begin{tabular}{|c|c|c|}
\hline Target gene & Primer sequence $\left(5^{\prime}-3^{\prime}\right)$ & Product-Size (bp) \\
\hline \multirow[t]{2}{*}{ ermB } & F-GATACCGTTTACGAAATTGG & \multirow[t]{2}{*}{364} \\
\hline & R-GAATCGAGACTTGAGTGTGC & \\
\hline \multirow[t]{2}{*}{ sul2 } & F-TCCGGTGGAGGCCGGTATCTGG & \multirow[t]{2}{*}{191} \\
\hline & R-CGGGAATGCCATCTGCCTTGAG & \\
\hline \multirow[t]{2}{*}{ tet $X$} & F-CAATAATTGGTGGTGGACCC & \multirow[t]{2}{*}{468} \\
\hline & R-TTCTTACCTTGGACATCCCG & \\
\hline \multirow[t]{2}{*}{ tetW } & F-GAGAGCCTGCTATATGCCAGC & \multirow[t]{2}{*}{168} \\
\hline & R-GGGCGTATCCACAATGTTAAC & \\
\hline \multirow[t]{2}{*}{ int/1 } & F-CTGGATTTCGATCACGGCACG & \multirow[t]{2}{*}{473} \\
\hline & R-ACATGCGTGTAAATCATCGTCG & \\
\hline \multirow[t]{2}{*}{ 16S-rRNA } & F-CCTACGGGAGGCAGCAG & \multirow[t]{2}{*}{193} \\
\hline & R-ATTACCGCGGCTGCTGG & \\
\hline
\end{tabular}

Table 2 Physical and chemical properties of fresh biochar (BC) and aged biochar (OBC) 


\begin{tabular}{|lll|}
\hline Parameter & Fresh biochar $(\mathrm{BC})$ & Aged biochar $(\mathrm{OBC})$ \\
\hline $\mathrm{pH}$ & 9.37 & 8.18 \\
\hline Ash content $(w t \%)$ & 5.00 & 6.05 \\
\hline $\mathrm{CEC}\left(\mathrm{cmol} \cdot \mathrm{kg}^{-1}\right)$ & 12.20 & 27.12 \\
\hline BET surface area $\left(\mathrm{m}^{2} \mathrm{~g}^{-1}\right)$ & 104.21 & 41.56 \\
\hline Pore volume $\left(\mathrm{cm}^{3} \mathrm{~g}^{-1}\right)$ & 0.057 & 0.024 \\
\hline Pore diameter $(\AA)$ & 21.93 & 22.73 \\
\hline C\% & 78.29 & 72.92 \\
\hline $\mathrm{H} \%$ & 2.47 & 2.43 \\
\hline O $\%$ & 11.08 & 15.03 \\
\hline $\mathrm{N} \%$ & 1.38 & 1.45 \\
\hline $\mathrm{H} / \mathrm{C}$ & 0.38 & 0.40 \\
\hline $\mathrm{O} / \mathrm{C}$ & 0.11 & 0.15 \\
\hline$(\mathrm{O}+\mathrm{N}) / \mathrm{C}$ & 0.12 & 0.17 \\
\hline
\end{tabular}

Table3 Summary of statistical significance from analysis of variance for ARGs abundance in soil

\begin{tabular}{llllll} 
Variation source & \multicolumn{2}{l}{ ARGs } & & & \\
\cline { 2 - 6 } & tetW & tetX & sul2 & ermB & int/ \\
\hline biochar type & $\mathbf{0 . 0 0 2}$ & $\mathbf{0 . 0 3 4}$ & 0.406 & $\mathbf{0 . 0 3 5}$ & $\mathbf{0 . 0 5 1}$ \\
\hline biochar level & $\mathbf{0 . 0 0 0}$ & 0.100 & $\mathbf{0 . 0 0 0}$ & $\mathbf{0 . 0 0 0}$ & 0.914 \\
\hline planting & $\mathbf{0 . 0 0 0}$ & $\mathbf{0 . 0 0 0}$ & $\mathbf{0 . 0 0 0}$ & $\mathbf{0 . 0 0 0}$ & $\mathbf{0 . 0 0 0}$ \\
\hline biochar type * biochar level & $\mathbf{0 . 0 0 0}$ & 0.129 & 0.832 & $\mathbf{0 . 0 0 0}$ & $\mathbf{0 . 0 5 3}$ \\
\hline biochar type * planting & $\mathbf{0 . 0 5 0}$ & $\mathbf{0 . 0 0 0}$ & $\mathbf{0 . 0 0 0}$ & $\mathbf{0 . 0 0 0}$ & $\mathbf{0 . 0 0 0}$ \\
\hline biochar level * planting & $\mathbf{0 . 0 0 0}$ & $\mathbf{0 . 0 0 0}$ & $\mathbf{0 . 0 0 0}$ & $\mathbf{0 . 0 1 8}$ & $\mathbf{0 . 0 0 0}$ \\
\hline biochar type * biochar level * planting & 0.167 & $\mathbf{0 . 0 0 0}$ & $\mathbf{0 . 0 0 0}$ & $\mathbf{0 . 0 0 0}$ & $\mathbf{0 . 0 0 0}$
\end{tabular}

Biochar type: fresh biochar/aged biochar

Biochar level: $0 \%, 1 \%$ and $2 \%$

Planting: rhizosphere soil/non-rhizosphere soil 


\section{Figures}
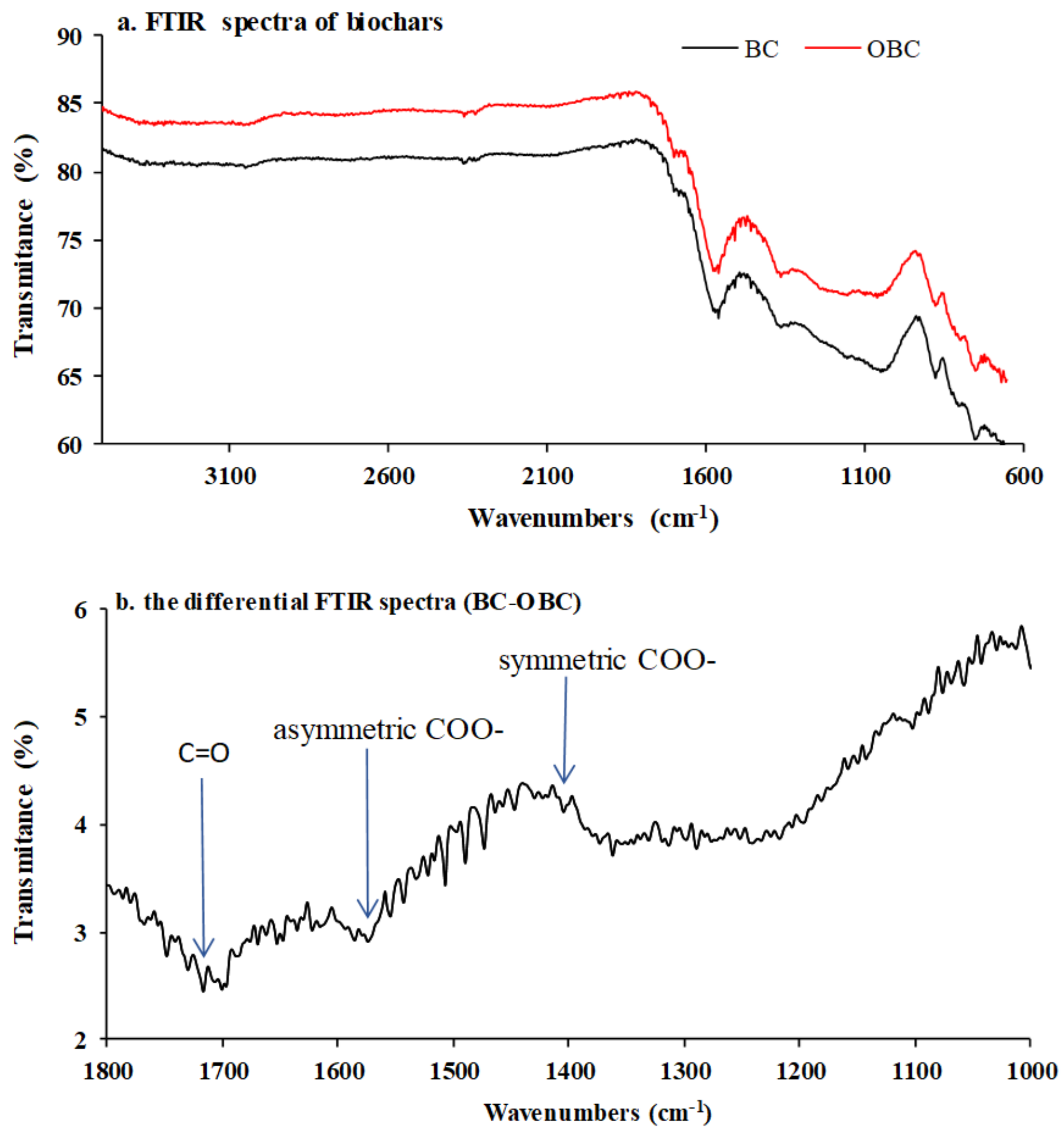

Figure 1

FTIR analysis of fresh biochar (BC) and aged biochar (OBC) 
a. $\mathrm{BC}$

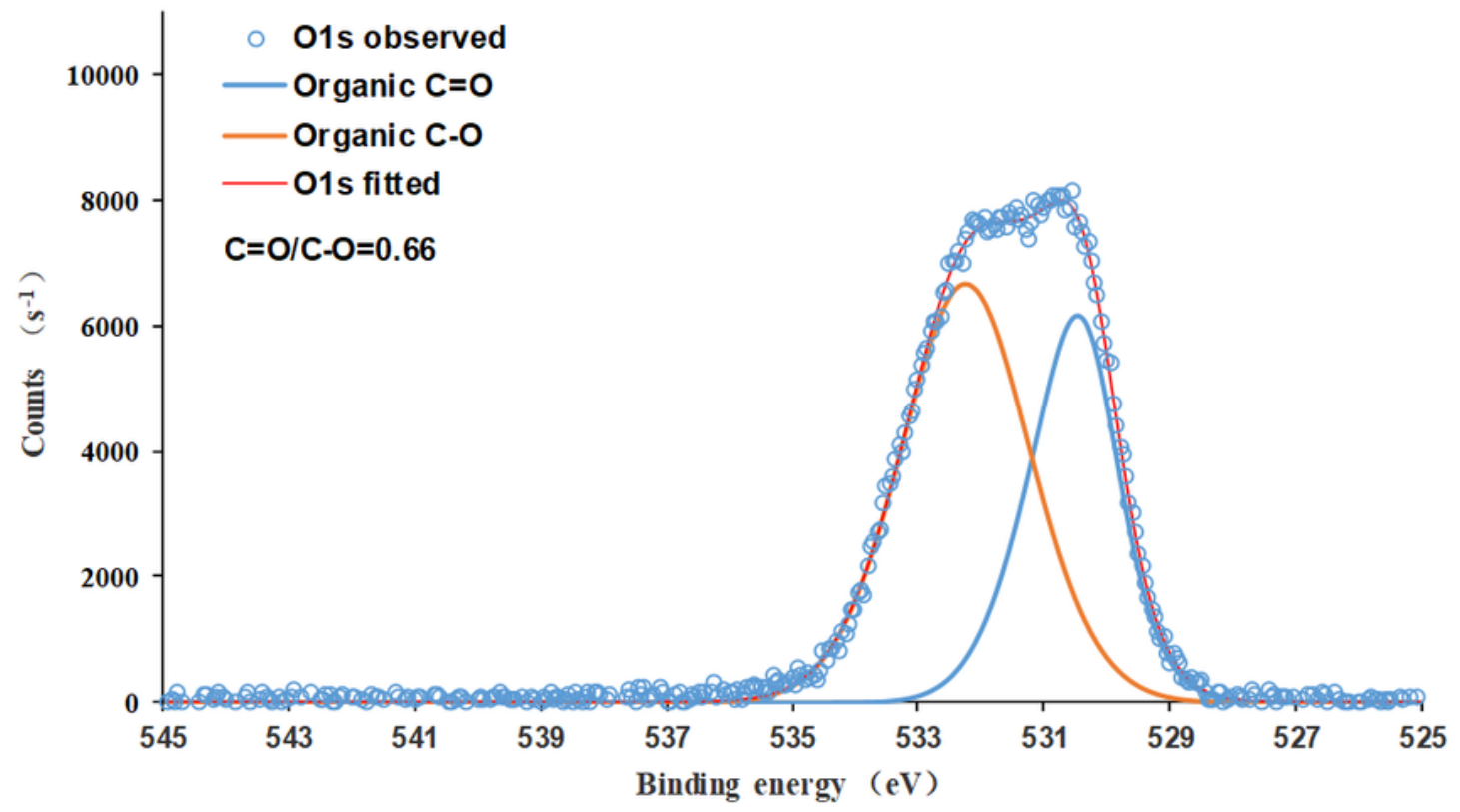

b. OBC

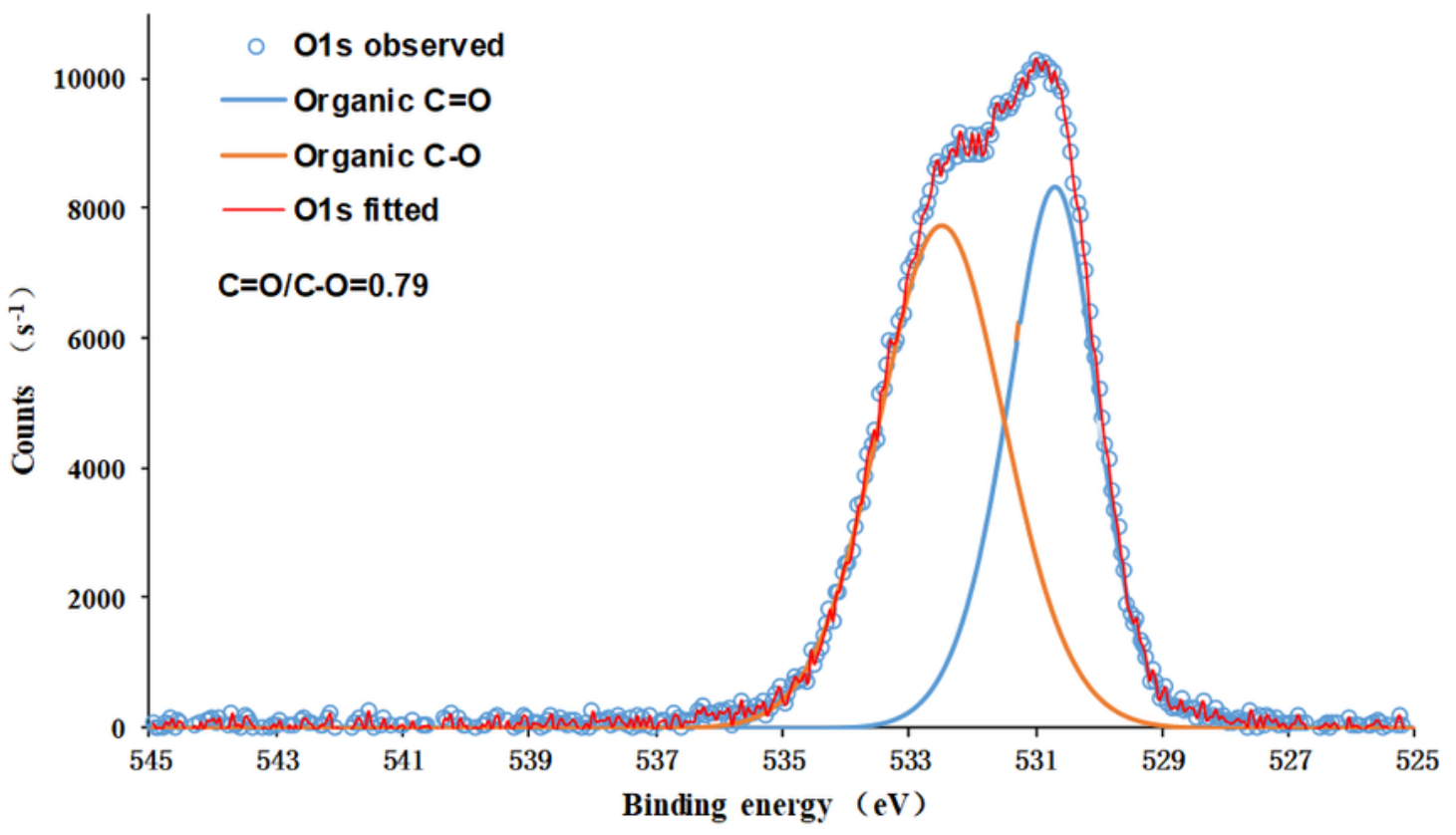

Figure 2

XPS analysis of fresh biochar (BC) and aged biochar (OBC) 

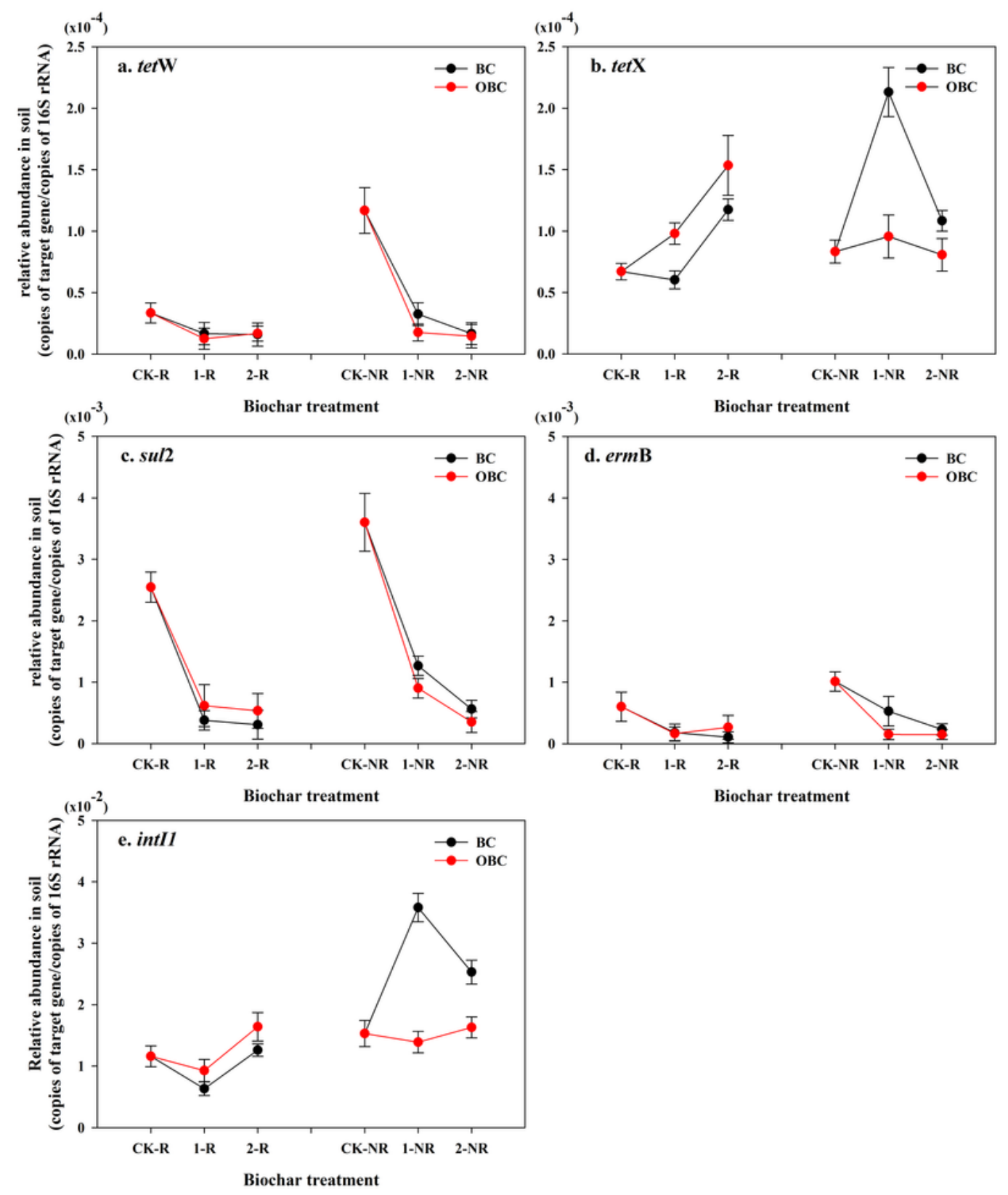

\section{Figure 3}

Effect of fresh biochar (BC) and aged biochar (OBC) on the relative abundance of ARGs in soil. R and NR in the $\mathrm{X}$-axis referred to as the rhizosphere soil and the non-rhizosphere soil, respectively. The numbers (1 and 2) before -R and -NR showed the biochar addition percent. CK was the soil without biochar. Values are means \pm standard deviation of triplicate measurements. 

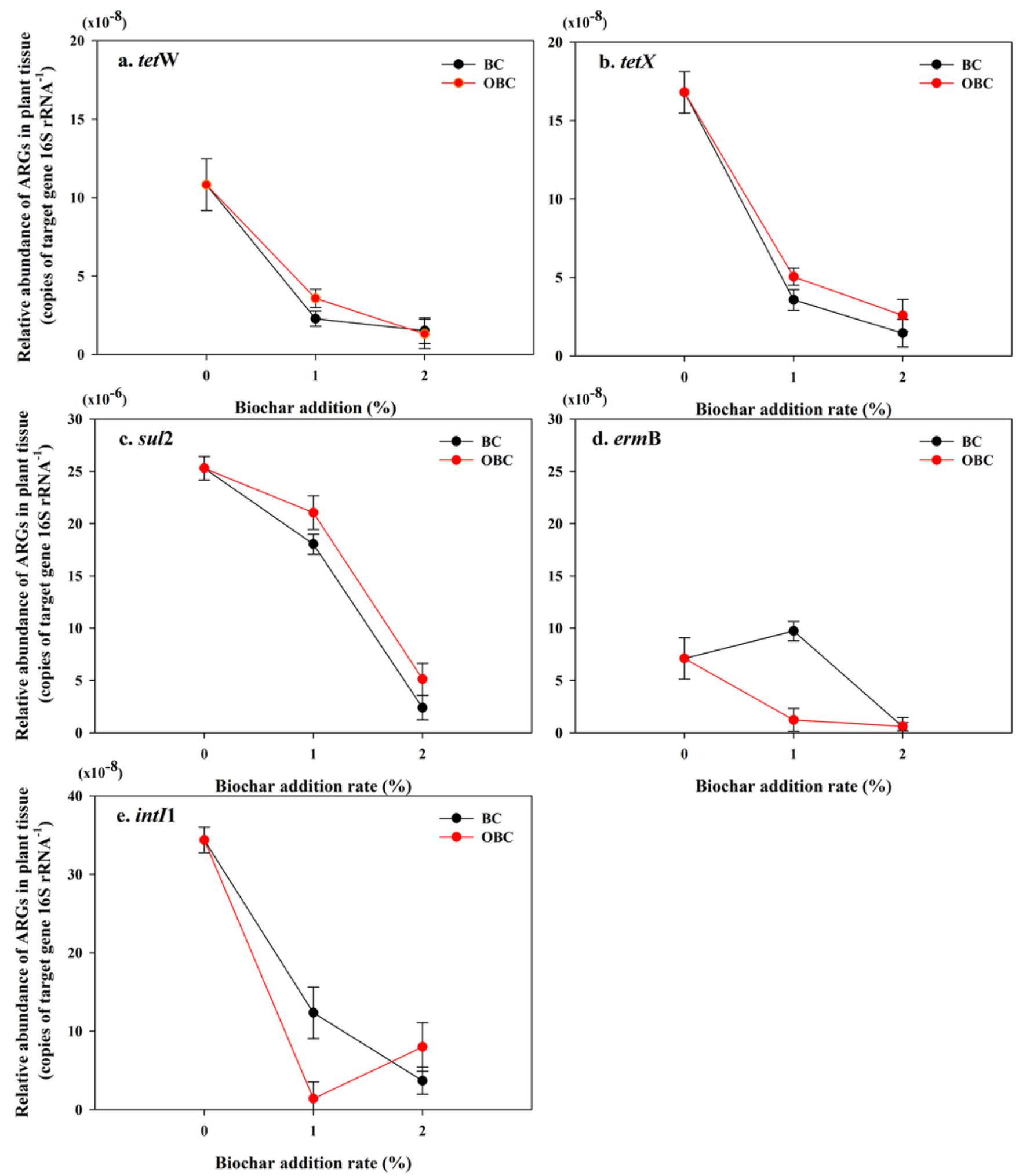

Biochar addition rate (\%)

\section{Figure 4}

Effects of fresh biochar (BC) and aged biochar (OBC) on the relative abundance of ARGs in pakchoi. Values are means \pm standard deviation of triplicate measurements. 
Page 21/21 